\title{
A COLETA SELETIVA SOLIDÁRIA INTEGRANDO UNIVERSIDADE, ESCOLA E CATADORES DE MATERIAL RECICLÁVEL EM SÃO GABRIEL (RS)
}

\author{
Patrícia de Oliveira Neves ${ }^{1}$ \\ Cíntia Barbosa Libel $^{2}$ \\ Letiéri da Rosa Freitas ${ }^{3}$
}

Resumo: A universidade promoveu através da Educação Ambiental, a sua articulação com a comunidade escolar em prol dos catadores, por meio de ações socioeducativas pautadas por projetos de extensão, com foco principal de qualiquantificar os resíduos secos produzidos no campus São Gabriel/UNIPAMPA e na escola municipal José Lima. Na universidade foram produzidos aproximadamente $379 \mathrm{Kg}$ de resíduos recicláveis, e na escola, 38,5 $\mathrm{Kg}$, que foram doados a duas associações de catadores. Além da doação de materiais, as ações dos projetos permitiram a aproximação de uma parcela da comunidade gabrielense da realidade dos agentes ambientais, incutindo nela 0 desejo de adoções de atitudes mais solidárias de respeito ao próximo e ao meio ambiente.

Palavras-chave: Educação Ambiental; Agentes Ambientais; UNIPAMPA.

${ }^{1}$ Universidade Federal do Pampa, São Gabriel, RS. E-mail: patrioline@hotmail.com

2 Universidade Federal do Pampa, São Gabriel, RS. E-mail: cintialibel@hotmail.com

3 Universidade Federal do Pampa, São Gabriel, RS. E-mail: letierifreitas@hotmail.com

Revbea, São Paulo, V.11, № 2: 357-372, 2016.

revista brasileira educação ambiental 


\section{Introdução}

Milhares de toneladas de lixo têm sido geradas diariamente, provenientes de diferentes fontes, entretanto, é o lixo domiciliar que representa o maior percentual gerado, constituindo num sério problema a ser enfrentado nos dias atuais (MAGALHÃES et al., 2004, p.3).

Para os municípios, a participação dos catadores (agentes ambientais) na gestão dos resíduos sólidos urbanos é de suma importância, pois, segundo a Política Nacional de Resíduos Sólidos (LEI FEDERAL 12.305, 2010), aqueles que implantarem a coleta seletiva com a participação de cooperativas ou outras formas de associação de catadores de materiais reutilizáveis e recicláveis terão acesso a recursos da União destinados a empreendimentos e serviços relacionados à limpeza urbana e ao manejo de resíduos sólidos.

Entretanto, para o processo de inclusão dos agentes ambientais em qualquer sistema de gestão municipal é imprescindível que a comunidade reconheça o valor dessa categoria de trabalhadores e considere o resíduo sólido reutilizável e reciclável como um bem econômico e de valor social, gerador de trabalho e renda e promotor da cidadania.

Para tanto, a Educação Ambiental é ferramenta essencial para estimular a conscientização da comunidade acadêmica/escolar e da comunidade local, tornando-a assim parte do processo de toda gestão municipal de resíduos sólidos urbanos. A inserção das comunidades escolar e universitária (educadores e alunos) no contexto deste projeto vem ao encontro da Política Nacional de Educação Ambiental (LEI FEDERAL 9.795, 1999), que determina que a dimensão ambiental deva ser amplamente tratada em todas as esferas do ensino.

No sentido de mitigar a problemática envolvendo a questão dos resíduos sólidos recicláveis no município de São Gabriel, o presente projeto teve por objetivo principal auxiliar, através da aliança entre a universidade, a escola e os agentes ambientais coletores de materiais recicláveis, a construção de uma nova sociedade, pautada no respeito, na inclusão social e no comprometimento com a preservação do meio ambiente.

\section{Metodologia}

As ações referentes à presente proposta contemplaram a comunidade acadêmica do campus São Gabriel da Universidade Federal do Pampa (UNIPAMPA); a comunidade escolar da escola municipal Presidente José Lima, e os agentes ambientais das Associações Municipais Sepé Tiaraju e Dignidade para Todos. A seguir serão descritas as ações relacionadas a cada categoria citada. 


\section{Etapa na comunidade acadêmica (UNIPAMPA - campus São Gabriel)}

A UNIPAMPA conta com dez unidades distribuídas em diferentes municípios da metade sul do Rio Grande do Sul. O município de São Gabriel conta com uma unidade, e, em 2010, para atender à legislação que institui a separação dos resíduos recicláveis descartados pelos órgãos e entidades federais (DECRETO FEDERAL 5.940, 2006), foram instituídas a coleta seletiva solidária e a comissão da coleta seletiva solidária (CCSS). Especificamente no campus São Gabriel, os resíduos secos recicláveis estavam sendo separados e doados aos agentes ambientais da associação Dignidade para Todos.

\section{Levantamento qualiquantitativo dos resíduos secos recicláveis na UNIPAMPA - campus São Gabriel}

Com a finalidade de estimar a quantidade de resíduos secos recicláveis produzidos nesta unidade da UNIPAMPA e doados aos agentes ambientais, foi registrado em 2013 um projeto de extensão intitulado "Levantamento qualiquantitativo dos resíduos sólidos produzidos no campus São Gabriel e a relação com a associação de catadores e escolas do município".

Os resíduos secos recicláveis considerados neste projeto foram apenas os materiais comercializáveis pelos agentes ambientais de São Gabriel, sendo eles: plásticos em geral (transparente, verde, branco, PET), papéis (branco, pardo, jornais), papelão e metal. As triagens foram realizadas na própria instituição, feita pela equipe do projeto e também por colaboradores eventuais.

As triagens ocorreram de abril a setembro de 2013, onde os resíduos foram separados conforme sua categoria (qualificação), seguido de uma pesagem (quantificação), contando com a utilização de uma balança analógica. Antes do início do levantamento, foram distribuídos novos coletores em todas as salas e laboratórios da universidade, e realizada instrução à equipe de terceirizados através de palestra educativa.

\section{Etapa na comunidade escolar}

\section{Projeto de extensão "Amigo do Catador"}

A comunidade escolar do município de São Gabriel foi contemplada a partir do projeto "Amigo do Catador", que fez parte do projeto de extensão "Levantamento qualiquantitativo dos resíduos sólidos produzidos no campus São Gabriel e a relação com a associação de catadores e escolas do município". O público alvo do projeto correspondeu aos alunos do terceiro e quarto anos da Escola Municipal de Ensino Fundamental José Lima, aos pais e/ou responsáveis desses alunos, e aos agentes ambientais da Associação Municipal Sepé Tiaraju.

A proposta principal foi apresentar o trabalho realizado pelos agentes ambientais coletores de materiais recicláveis, em uma tentativa de conscientizar as crianças e seus responsáveis sobre a relevante importância socioambiental dessa categoria de trabalhadores, estimulando cada cidadão a

revista brasileira educação ambiental 
tornar-se um agente ativo e participativo no processo da coleta seletiva solidária e na preservação do meio ambiente. Devido a essa importância, buscou-se estimular a substituição do termo 'catador' por 'agente ambiental', termo que os próprios trabalhadores estão aderindo.

Visando atingir a sua proposta inicial, a ação principal do projeto foi a de estimular a coleta seletiva na casa de cada aluno alvo, que levaria para a escola os resíduos separados em casa, e por último, doaria para os agentes ambientais da associação municipal. A seguir são descritas as atividades desenvolvidas na escola relativas ao projeto "Amigo do Catador".

\section{Aplicação do questionário}

Como primeira ação, foi aplicado um questionário aos alunos e a seus responsáveis, no intuito de averiguar o conhecimento relativo às temáticas 'resíduos urbanos', 'coleta seletiva' e 'agentes ambientais'.

\section{Palestras educativas}

Em encontros posteriores, foram ministradas palestras educativas a fim de apresentar a proposta do projeto, além de abordar as questões consideradas no questionário previamente aplicado.

Para a conscientização dos pais e/ou responsáveis e para orientá-los de como proceder à separação correta dos resíduos em casa, também foi ministrada uma palestra direcionada a este grupo.

\section{Dinâmicas de conscientização socioambiental}

Além das palestras educativas, os alunos participaram de dinâmicas com foco na preservação ambiental, especialmente na importância de conservar os rios e a cidade limpos.

\section{Levantamento qualiquantitativo dos resíduos secos recicláveis na escola José Lima}

Foi realizado um levantamento qualiquantitativo dos resíduos secos recicláveis levados de casa pelos alunos, à semelhança daquele trabalho desenvolvido no campus São Gabriel da UNIPAMPA.

O levantamento contou com triagens mensais, iniciadas em setembro de 2013, finalizando em dezembro do mesmo ano. Em cada triagem, cada categoria de resíduos (papel, plástico e metal) foi pesada com a utilização de uma balança analógica. Além dos resíduos domiciliares, foram também incluídos nas avaliações aqueles produzidos na própria escola. As triagens foram realizadas no pátio da escola, coordenadas pela equipe do projeto e contando com a participação de integrantes da associação Sepé Tiaraju. No final de cada triagem, os resíduos foram doados para os agentes ambientais dessa associação.

Revbea, São Paulo, V.11, № 2: 357-372, 2016. 


\section{Resultados e Discussão}

\section{UNIPAMPA - campus São Gabriel}

\section{Levantamento qualiquantitativo dos resíduos secos recicláveis na UNIPAMPA-campus São Gabriel}

\section{Implantação de novos coletores}

Uma das ações relacionadas ao projeto de extensão "Levantamento qualiquantitativo dos resíduos sólidos produzidos no campus São Gabriel e a relação com a associação de catadores e escolas do município" foi a distribuição de novos coletores nas dependências da instituição, visando facilitar o processo da coleta seletiva solidária. Assim, foram disponibilizados dois coletores padronizados (Figura 1) em cada sala de aula, em corredores, em sala de servidores, e em laboratórios de ensino e pesquisa. A separação do resíduo orgânico dos demais resíduos secos é fundamental para não contaminar o resíduo reciclável, que acaba perdendo muito valor comercial.

Em alguns pontos externos dos prédios da instituição existem disponibilizados para a coleta seletiva, conjuntos de coletores seguindo o padrão estabelecido pela legislação específica (CONAMA 275, 2001), entretanto, a definição de apenas dois coletores simplifica o processo, além de ocupar menos espaço dentro dos prédios.
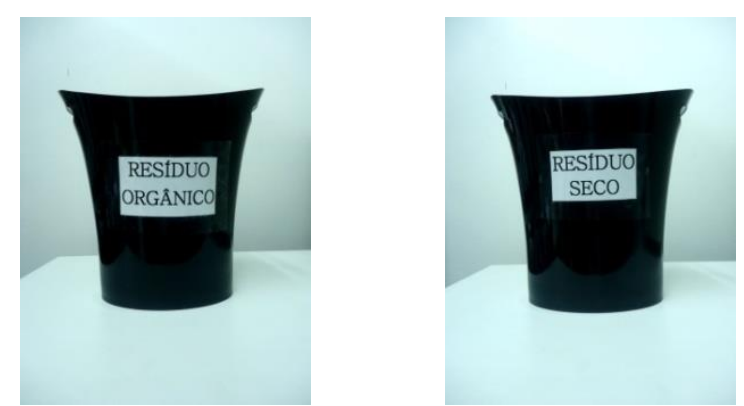

Figura 1: Coletores distribuídos nas dependências da UNIPAMPA - campus São Gabriel.

\section{Instrução à equipe de terceirizados}

A equipe de terceirizados, especialmente àquela relacionada à limpeza, corresponde a um grupo chave no processo da coleta seletiva, uma vez que é quem recolhe e lida diretamente com os resíduos. Para criar uma efetiva parceria entre a equipe do projeto e esse grupo, considerou-se necessário alguns esclarecimentos a respeito da importância da coleta seletiva para o meio ambiente, em especial, para os agentes ambientais que recolhem os materiais recicláveis.

Com este objetivo, foi ministrada uma palestra educativa aos terceirizados (Figura 2), abordando diversas questões relacionadas às temáticas 'resíduos', 'coleta seletiva solidária' e 'legislação ambiental'. 


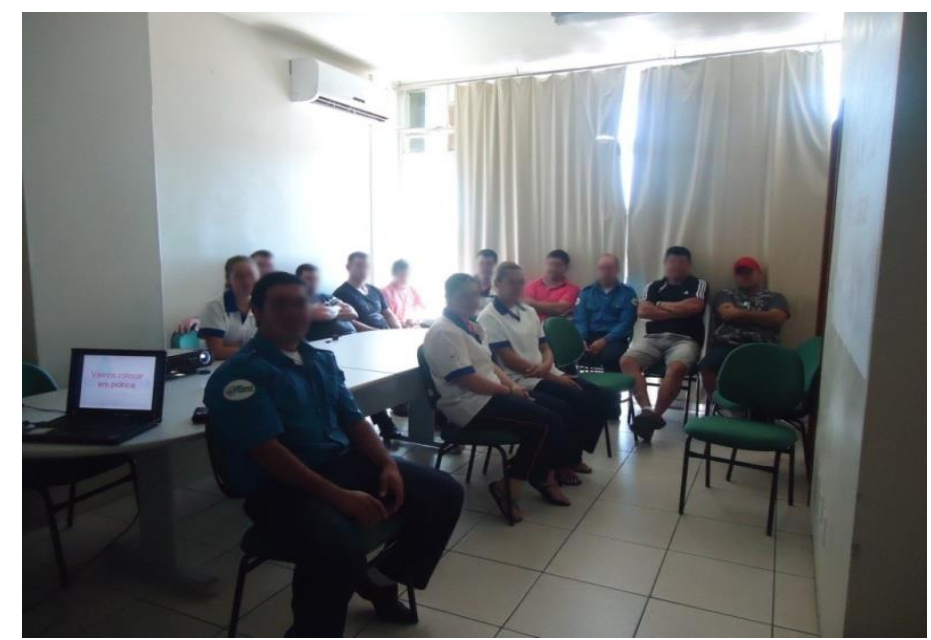

Figura 2: Equipe de terceirizados na palestra educativa.

\section{Triagens}

Os dados provenientes do levantamento qualiquantitativo realizado na UNIPAMPA/ campus São Gabriel correspondem a seis meses de avaliação (Tabela 1).

Foram produzidos aproximadamente $379 \mathrm{Kg}$ de materiais recicláveis, distribuídos entre papel, papelão e plástico.

A UNIPAMPA, por corresponder a uma instituição de ensino e ainda em fase de implantação, gera uma quantidade expressiva de papel branco e de papelão, devido à constante compra de equipamentos e de outros materiais, justificando o elevado volume dessas categorias.

As triagens foram realizadas na própria instituição e, devido ao elevado montante de resíduo produzido, foram realizadas semanalmente (Figura 3). No final de cada avaliação, os materiais ficavam temporariamente armazenados e eram levados para o galpão de triagem (Figura 4), sede da associação "Dignidade para Todos".

Tabela 1: Resultado do levantamento qualiquantitativo dos resíduos secos recicláveis produzidos na UNIPAMPA/Campus São Gabriel no período de abril a setembro de 2013.

\begin{tabular}{lcccc}
\hline \multirow{2}{*}{ Triagens } & \multicolumn{4}{c}{ Tipos de materiais recicláveis $\mathbf{( K g )}$} \\
\cline { 2 - 5 } & Papel & Papelão & Plástico & Total/mês \\
\hline Abril & 7,0 & 0 & 2,0 & 9,0 \\
Maio & 64,5 & 0 & 6,5 & 71,0 \\
Junho & 20,5 & 30,0 & 5,0 & 55,5 \\
Julho & 21,5 & 15,0 & 8,0 & 44,5 \\
Agosto & 33,0 & 21,0 & 9,0 & 63,0 \\
Setembro & 26,0 & 95,0 & 15,5 & 136,5 \\
\hline Total & 172,5 & 161,0 & 46,0 & $\mathbf{3 7 9 , 5}$ \\
\hline
\end{tabular}

Revbea, São Paulo, V.11, № 2: 357-372, 2016. 


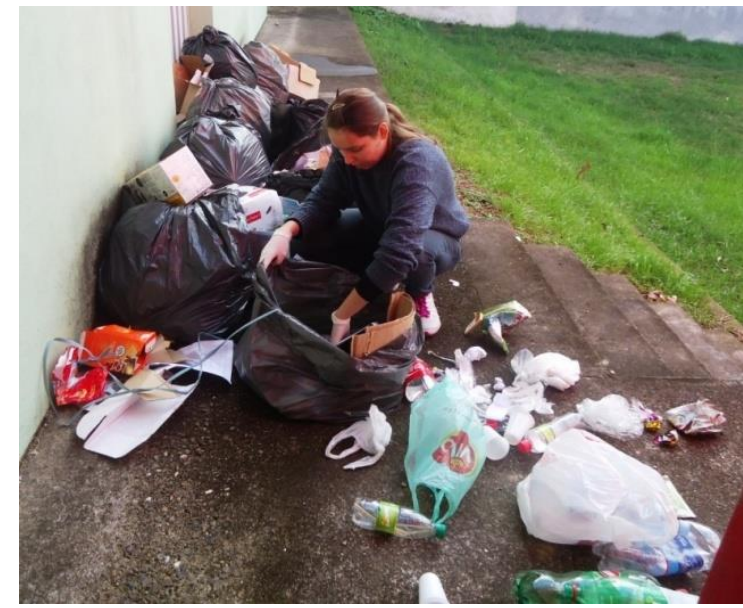

Figura 3: Triagem sendo realizada na UNIPAMPA - campus São Gabriel.

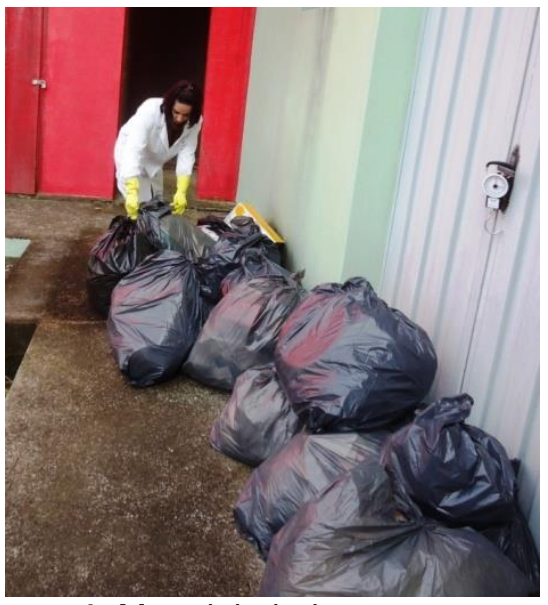

Figura 4: Material triado pronto para ser levado para o galpão dos agentes ambientais.

\section{Escola Municipal José Lima}

\section{Projeto de extensão "Amigo do Catador"}

Os educadores, de um modo geral, apresentam dificuldades e, algumas vezes, até certa resistência em inserir a Educação Ambiental em seus conteúdos curriculares, devido à existência de poucas referências sobre práticas educativas relacionadas ao ambiente (SILVA; JOIA, 2008, p. 138).

Os projetos de extensão, por sua vez, representam uma alternativa muito válida a essa situação, pois conseguem inserir a Educação Ambiental no contexto da comunidade escolar de uma forma bastante eficaz.

O projeto "Amigo do Catador" teve o propósito de trabalhar a Educação Ambiental dentro da comunidade escolar da escola José Lima, focando a coleta seletiva solidária, no sentido de conscientizar alunos, educadores e paisłresponsáveis sobre a importância desse processo na inclusão social e preservação do meio ambiente.

A coleta seletiva é um dos principais instrumentos de intervenção na realidade socioambiental, com forte caráter educativo, por possibilitar a mobilização da comunidade na busca de alternativas para a melhoria de seu ambiente de vida, transformando os cuidados com o lixo em exercício de cidadania (COSTA et al., 2014, p.36).

O projeto "Amigo do Catador" iniciou em agosto de 2013, finalizando em dezembro do mesmo ano, contemplando quatro turmas ao todo, abrangendo 76 alunos. A seguir são descritas as ações relativas a ele. 


\section{Aplicação do questionário}

O questionário foi aplicado aos 76 alunos, que responderam na própria sala de aula durante o expediente normal. Foi composto por sete questões (seis de múltipla escolha, e uma discursiva).

As questões elaboradas e o percentual das respostas dadas pelos entrevistados constam nas Figuras 5 a 11.

As questões focaram no processo de coleta seletiva como um todo, tentando inferir o grau de esclarecimento e envolvimento das crianças nesse processo, na escola e em casa. Além disso, focaram também nos agentes ambientais, visto que o principal objetivo do projeto era o de aproximar a comunidade escolar, especialmente as crianças, desse grupo de trabalhadores.

A participação dos alunos era importante, principalmente para que pudessem estimular e incentivar a coleta seletiva em sua residência. Dessa forma, a questão "Você tem interesse em ajudar o catador, separando os materiais recicláveis em sua casa?" foi elaborada com o intuito de averiguar o quanto desses alunos estariam dispostos a participar efetivamente do projeto, estimulando seus pais e/ou responsáveis a serem parceiros da proposta.

Quando questionados sobre o porquê do interesse, as respostas se dividiram entre a empatia pelo catador e o interesse em preservar o meio ambiente (cidade limpa, rios limpos, menos poluição). Quanto às respostas negativas, os entrevistados apenas apontaram a falta de interesse como justificativa ao desinteresse em colaborar.

Figuras 5-11: Questões elaboradas aos alunos alvo do projeto "Amigo do Catador" e os respectivos percentuais das respostas dadas.
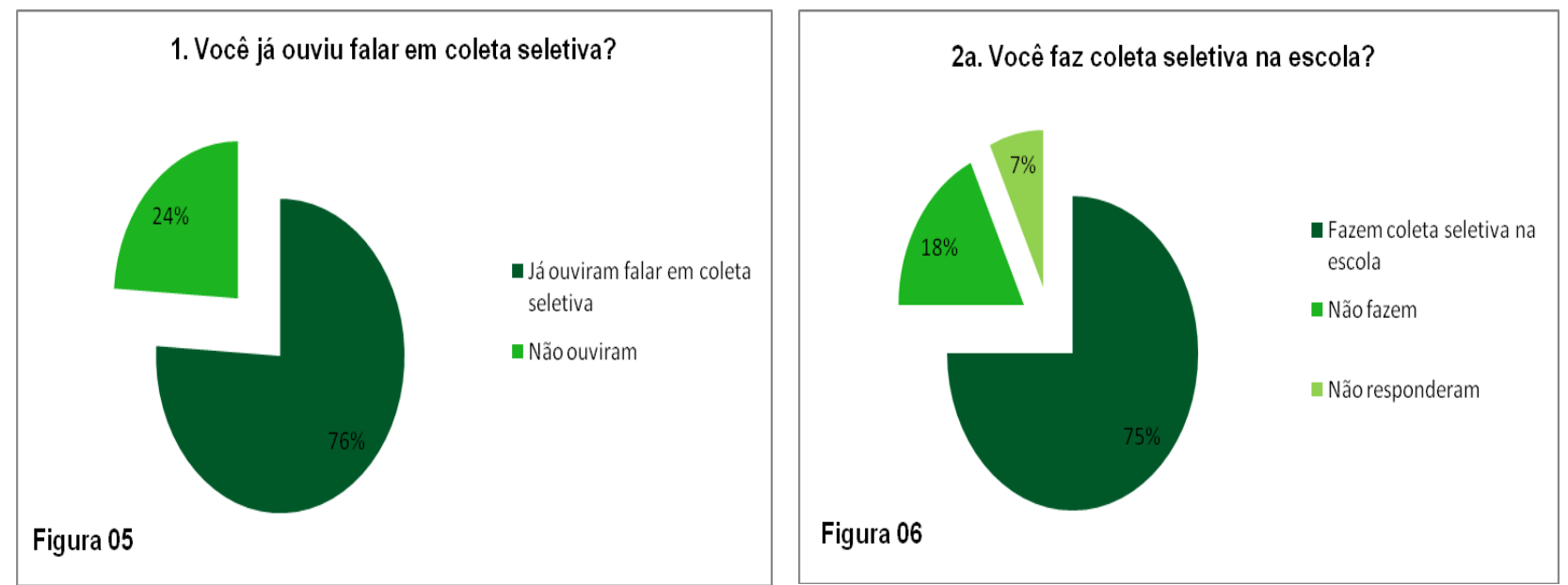

Revbea, São Paulo, V.11, № 2: 357-372, 2016. 
2b. Você faz coleta seletiva em sua casa?

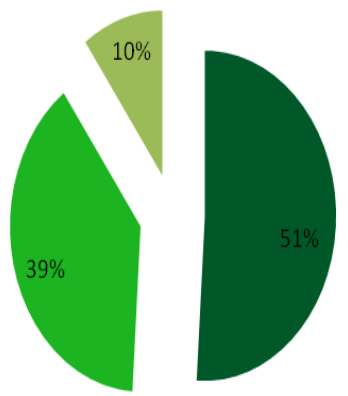

Figura 07
- Fazem coleta seletiva em casa

não fazem

Não responderam
4. Marque os materiais que você acha que o catador coleta e vende?

Figura 09
3. Você conhece o trabalho que um catador de material reciclável faz?

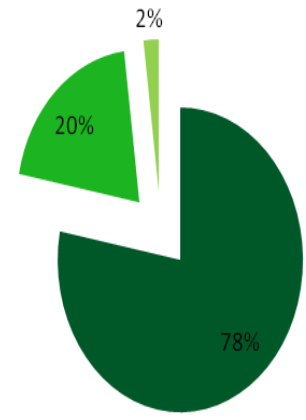

- Conhecem o trabalho do catador

não conhecem

Não responderam

Figura 08
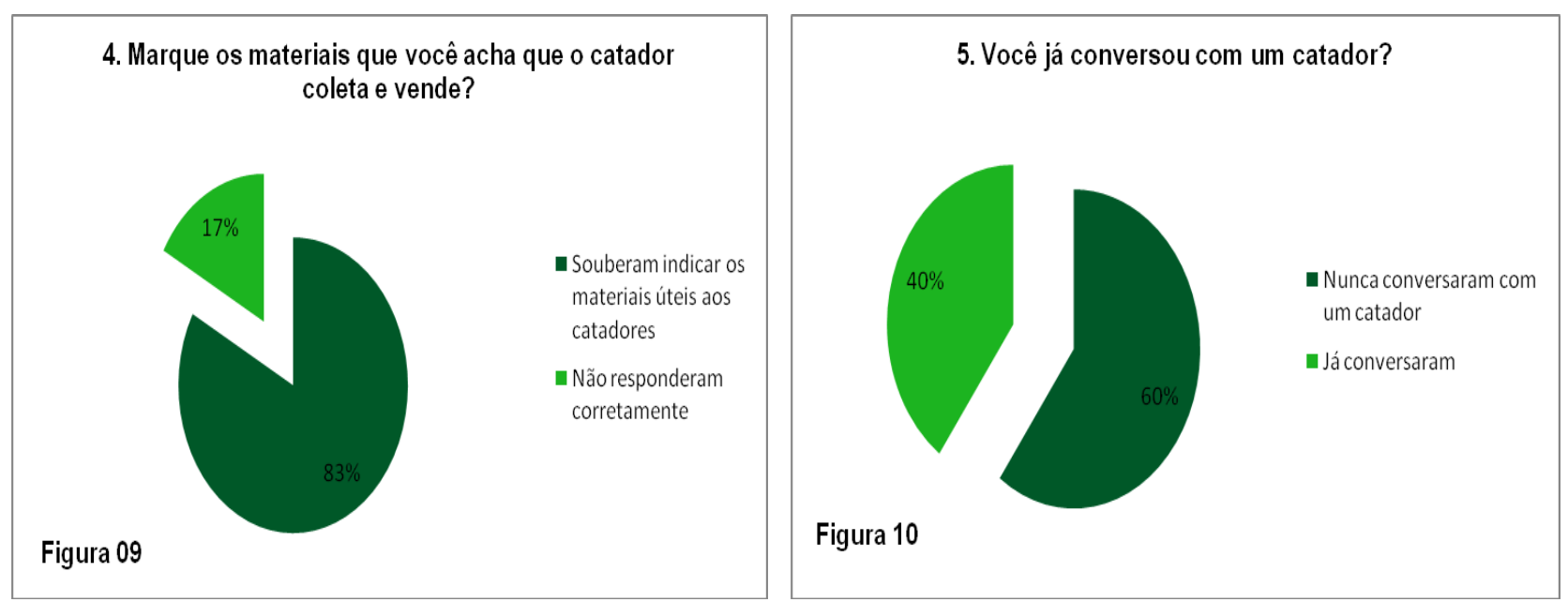

6. Você tem interesse em ajudar o catador separando os materiais recicláveis em sua casa?

Figura 11

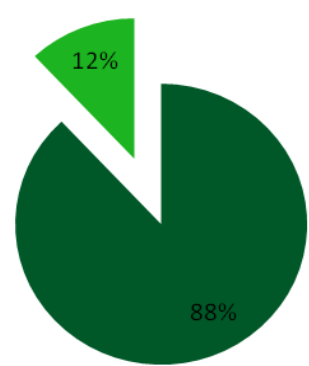

- Alunos interessados em ajudar o catador

- Alunos não interessados

O questionário aplicado aos pais e/ou responsáveis abrangeu 16 pessoas (Figura 12), correspondendo a $21 \%$ do total de alunos entrevistados. Composto por oito questões de múltipla opção, teve o intuito de averiguar o conhecimento dessa parcela da população sobre a gestão dos resíduos 
urbanos de São Gabriel, como administra os resíduos produzidos em casa, e qual a sua relação com os agentes ambientais. A partir das respostas foi possível perceber o grau de discernimento e comprometimento em se envolver de forma mais efetiva no gerenciamento dos resíduos urbanos, o que servirá até mesmo para nortear futuras ações do poder público para o sucesso de um plano de gestão municipal a ser implementado.

A participação dos pais e/ou responsáveis era fundamental, e as respostas dadas à questão 8 revelaram que a grande maioria dessa parcela entrevistada mostrou-se disposta em participar do projeto "Amigo do Catador". Essa adesão pode ter sido facilitada pelo fato de não ser necessário deixar os resíduos armazenados dentro de casa. MANDELLI (1997 apud De CONTO, 2010, p.23), ao estudar sobre as situações com as quais a população urbana se defronta ao manejar resíduos sólidos urbanos no âmbito residencial, identificou como uma das variáveis que interferem no comportamento dessa população a inexistência ou inadequação de espaços para armazenamento de tais resíduos.

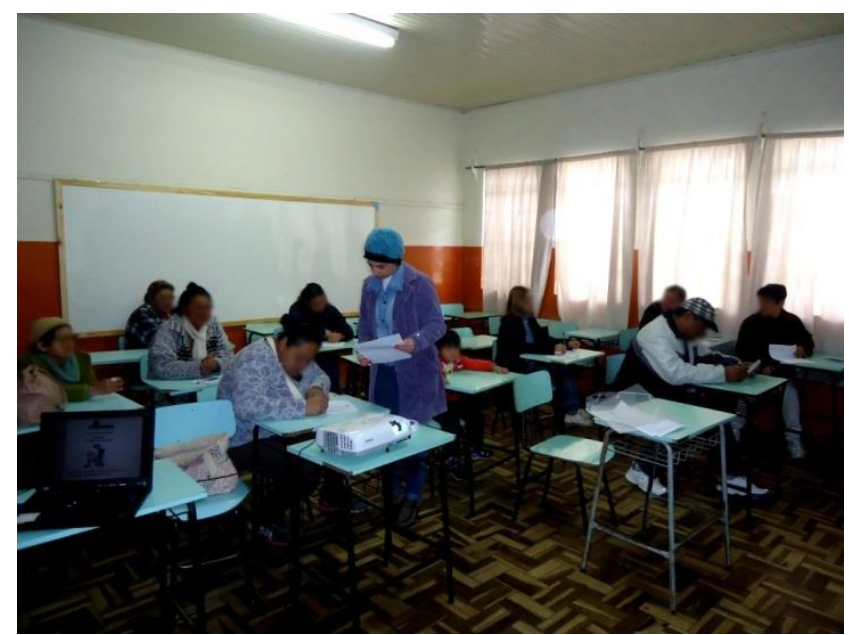

Figura 12: Grupo de pais e/ou responsáveis respondendo ao questionário.

Figuras 13-20: Questões elaboradas aos responsáveis dos alunos e os respectivos percentuais das respostas dadas, no projeto "Amigo do Catador".

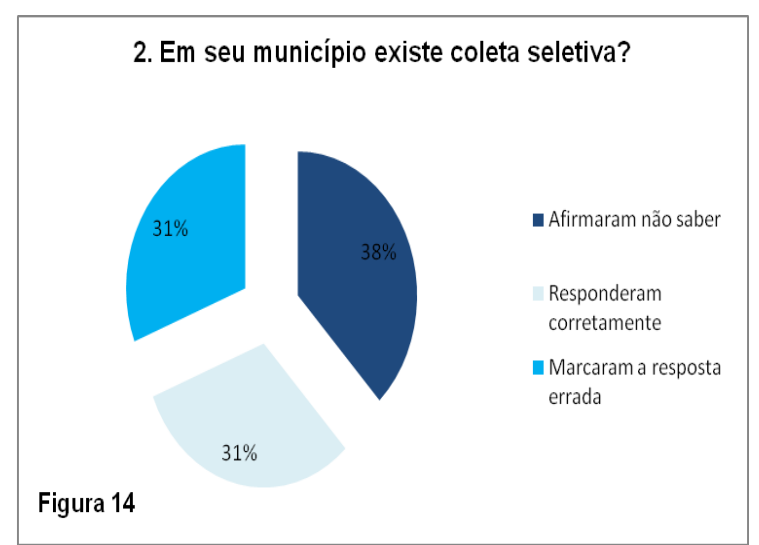

Revbea, São Paulo, V.11, № 2: 357-372, 2016. 
3. Qual o destino dos resíduos coletados pelo caminhão do lixo?

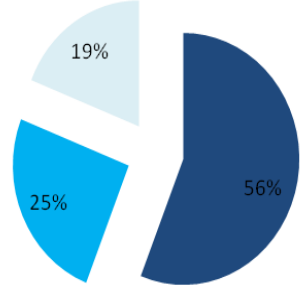

Figura 15
- Responderam corretamente

Afirmaram não saber

Marcaram a resposta errad
5. O que você faz com os resíduos secos separados em casa?

Figura 17

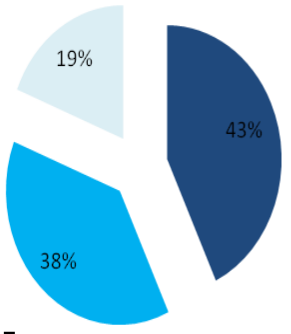

Entrega eventualmente para um catador

Nunca entrega para um catador

Prioriza entregar para um catador
7. Você acha importante o trabalho que um catador (agente ambiental) faz?

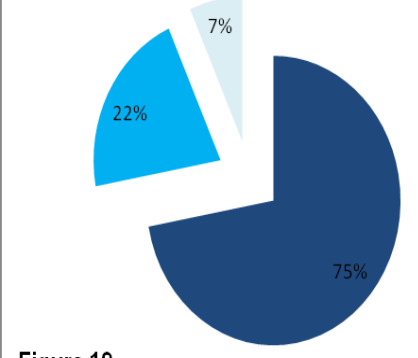

Figura 19
- Acham importante

- Afirmaram desconhecer que faz um catador

Não acham important

\section{Palestras educativas}

Segundo Silva e Joia (2008, p. 149), a Educação Ambiental pode ser considerada como um processo transformador e conscientizador, visando interferir diretamente nos hábitos e atitudes dos cidadãos. As palestras educativas, por sua vez, representam uma forma de pôr em prática esse processo. 
Ao todo foram ministradas duas palestras educativas (Figura 21), cujas temáticas abordaram o processo de coleta seletiva do município de São Gabriel e o trabalho desempenhado pelos agentes ambientais, enfatizando os temas abordados no questionário previamente aplicado.

Lançando-se mão da Educação Ambiental, visou-se conscientizar o público alvo sobre a importância do trabalho realizado por essa categoria de trabalhador, em uma tentativa de transformar a postura de cada aluno frente a essa importante questão. Segura (2001, p. 31), afirma que a construção de uma nova sociedade implica na aquisição de uma postura crítica diante da realidade, sem a qual não há transformação social.

Além das palestras, os alunos tiveram um encontro com a agente ambiental da associação Sepé Tiaraju (Figura 22), que explicou o trabalho que realizam e pediu a participação de cada um nesse projeto, separando os resíduos secos em casa.

Para os pais e/ou responsáveis também foi apresentada a palestra educativa com foco na orientação de como proceder à coleta seletiva em casa. Como ressaltam Abdala et al. (2008, p. 5), a Educação Ambiental pode mudar a concepção e a prática da maioria das pessoas em relação ao seu comportamento, hábitos e atitudes na gestão de resíduos sólidos. A efetiva colaboração e comprometimento dessas pessoas eram fundamentais, uma vez que são elas quem de fato administram os resíduos produzidos em casa. Para Brum e Silveira (2011, p. 610), a defesa do meio ambiente passou a ser responsabilidade de todos, sendo necessário tratar do tema no universo escolar com o envolvimento não só da comunidade escolar, mas também dos membros de toda a sociedade.

Ao todo participaram da palestra 16 pais, de um total de 76 alunos. A palestra aconteceu após o preenchimento do questionário.

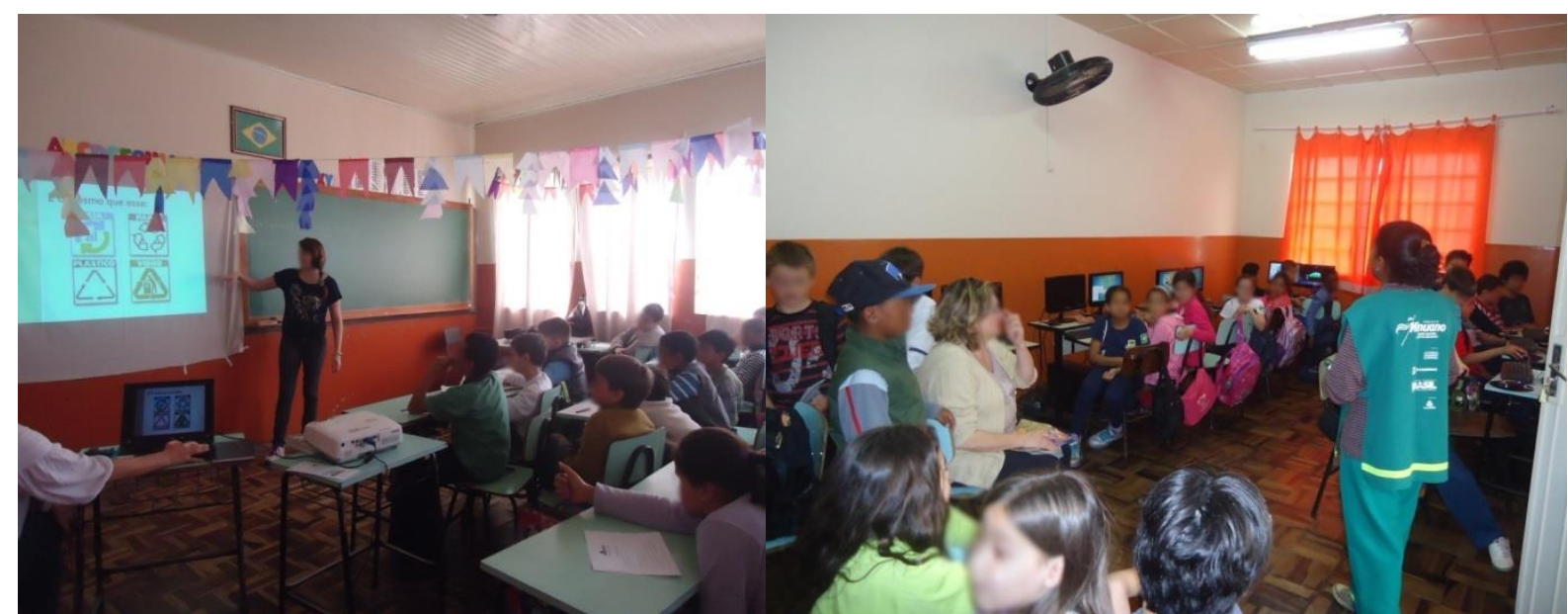

Figura 21: Palestra educativa direcionada aos alunos da escola José Lima.

Figura 22: Visita da agente ambiental integrante da associação Sepé Tiaraju na escola José Lima. 


\section{Dinâmicas de conscientização socioambiental}

Além das palestras educativas, foram realizadas dinâmicas de conscientização socioambiental, as quais contemplaram "ecoleitura", "pescaria no Rio Vacacai" e "coleta seletiva" (Figuras 23, 24 e 25).

Para a "ecoleitura" foi utilizado o livro infantil "Era uma vez... um coquinho amarelinho" de autoria de Lurdes Zanchetta da Rosa e de Ângela Medeiros de Assis Brasil, que enfatiza a importância ecológica das matas ciliares. O enfoque foi dado à preservação do rio Vacacaí, que passa pelo município de São Gabriel.

A "Pescaria no Rio Vacacaí" foi uma atividade prática lúdica, que teve a intenção de mostrar a importância de um rio limpo na vida das pessoas, em uma tentativa de conscientizar as crianças a jogarem o "lixo" nas lixeiras.

Por fim, a atividade ligada à dinâmica da "coleta seletiva" visou estimular a separação correta dos resíduos, onde foram escolhidos diferentes materiais recicláveis representantes das diferentes categorias (papel, metal, plástico, vidro, orgânico) e os alunos deveriam escolher um material e dispor no coletor específico.

As dinâmicas foram coordenadas pela Prof ${ }^{a}$ Lurdes Zanchetta, com a participação de acadêmicos do curso de Ciências Biológicas (Licenciatura) e de Gestão Ambiental da UNIPAMPA - campus São Gabriel.

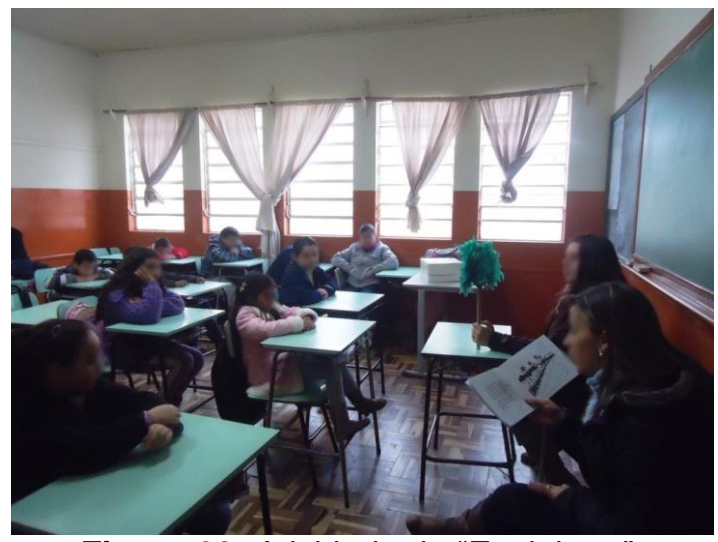

Figura 23: Atividade de "Ecoleitura".

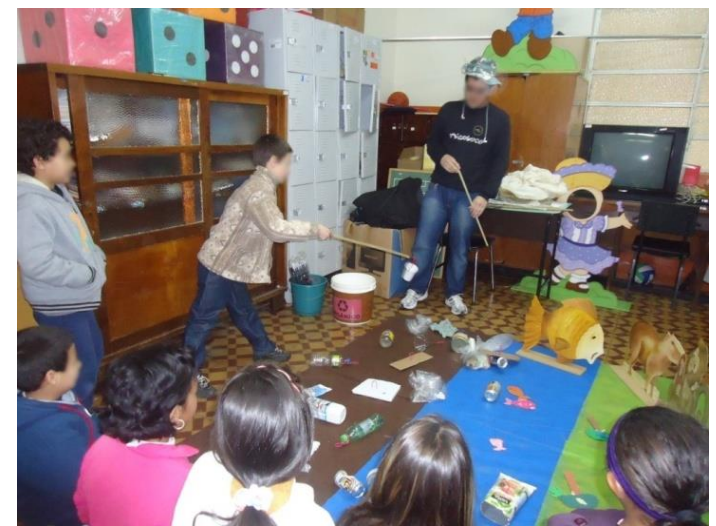

Figura 24: Atividade "Pescaria no rio Vacacaí".

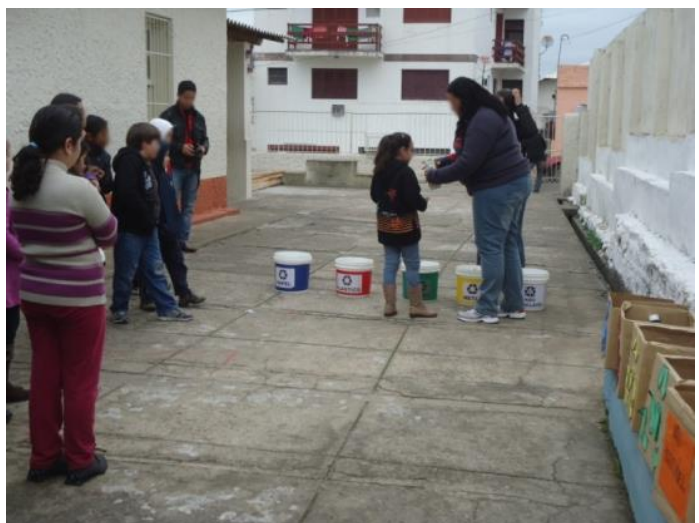

Figura 25: Atividade "Coleta seletiva".

Revbea, São Paulo, V.11, № 2: 357-372, 2016.

revista brasileira

educação ambiental 


\section{Levantamento qualiquantitativo dos resíduos secos recicláveis na escola José Lima}

A primeira triagem realizada na escola José Lima ocorreu em setembro de 2013. Ao todo foram três triagens realizadas, produzindo no final um valor aproximado de $18 \mathrm{Kg}$ de plástico, $1 \mathrm{Kg}$ de metal, $15 \mathrm{Kg}$ de papelão e $4,5 \mathrm{Kg}$ de papel. As garrafas PET $e$ as latinhas de metal foram as principais representantes da categoria dos plásticos e dos metais, respectivamente.

As triagens tiveram a participação da equipe do projeto, dos alunos e dos agentes ambientais da associação municipal Sepé Tiaraju (Figura 26).

A participação ativa dos alunos nessa ação foi de grande importância porque permitiu a efetiva participação no processo de triagem, somado à participação em casa, quando do incentivo aos pais de realizarem a separação dos resíduos em seu domicílio a fim de colaborar com o trabalho dos agentes ambientais.

Os resíduos armazenados corresponderam especialmente àqueles trazidos pelos alunos de casa, onde a escola contribuiu basicamente com a doação de caixas de papelão.

No final de cada triagem, os resíduos separados eram doados aos agentes ambientais da associação municipal Sepé Tiaraju (Figura 27).

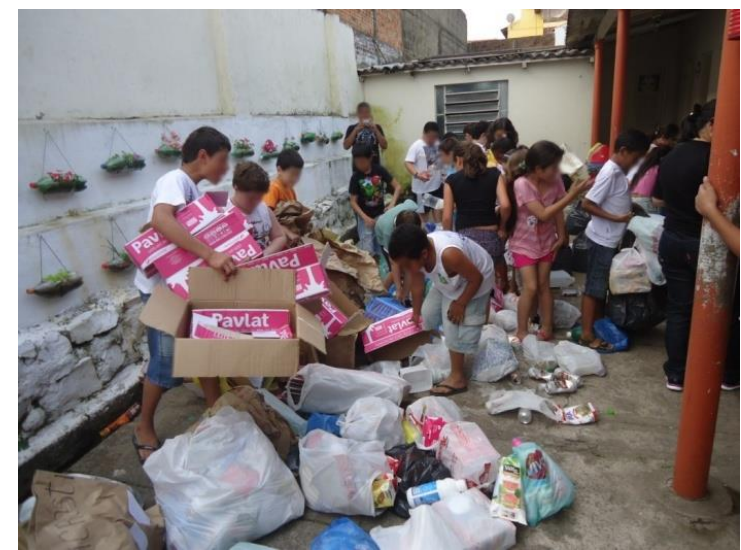

Figura 26. Alunos da escola José Lima participando da triagem dos resíduos.

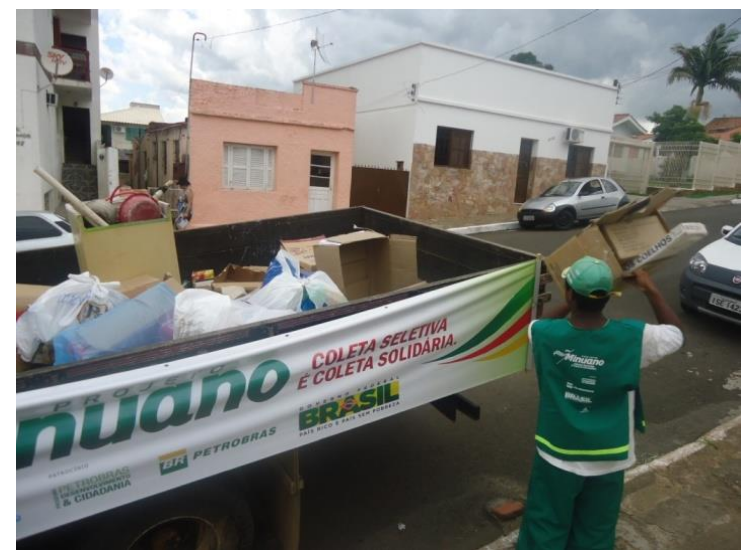

Figura 27. Terceira triagem na escola José Lima: agentes ambientais recolhendo os resíduos doados pelos alunos.

\section{Conclusão}

As ações desse projeto foram importantes porque promoveram a integração entre a universidade, a comunidade escolar e os agentes ambientais locais.

As atividades desenvolvidas junto à comunidade escolar possibilitaram o 
oportunizando-as de melhor conhecer o papel socioambiental que desempenham, e assim, tornarem-se parceiros.

Além disso, percebeu-se que os alunos têm um esclarecimento teórico sobre a questão dos resíduos urbanos e suas implicâncias socioambientais, apresentando, assim, empatia pelo agente ambiental e um respeito pelo meio ambiente. Com foco também no público adulto (responsáveis dos alunos), foi possível inferir sobre o conhecimento dessa parcela da população sobre a temática, revelando que, embora os dados apontem que uma boa parcela detém um bom conhecimento, muitos ainda desconhecem como se dá a gestão dos resíduos urbanos em seu município e o trabalho realizado por um agente ambiental.

Esses dados são importantes para nortear futuras ações de Educação Ambiental, especialmente pelo poder público local, uma vez que o estímulo à coleta seletiva em casa corresponde a um passo importante no processo de gestão dos resíduos urbanos, cujo êxito depende muito da colaboração da comunidade em geral.

\section{Agradecimentos}

Agradecemos ao apoio financeiro do Programa de Bolsas de Desenvolvimento Acadêmico (PBDA) da Universidade Federal do Pampa (UNIPAMPA) pela bolsa concedida à acadêmica Cíntia Libel. Agradecemos a todos que de alguma forma contribuíram para a execução desse trabalho, em especial à diretora e ao corpo docente da Escola Municipal José Lima; à Profa. Lurdes Zancheta e seus alunos; à bióloga Brisa Marciniak pela edição das fotos; e aos agentes ambientais das associações municipais "Dignidade para Todos" e "Sepé Tiaraju".

\section{Referências}

ABDALA, W.J.S; RODRIGUES, F.M.; ANDRADE, J.B.L. Educação Ambiental e coleta seletiva: importância e contextualização no mundo atual. Travessias: Pesquisa em Educação, Cultura, Linguagem e Arte, n. 2: p. 01-12, 2007.

BRASIL. Lei no 9.795, de 27 abril de 1999. Dispõe sobre a Educação Ambiental, institui a Política Nacional de Educação Ambiental e dá outras providências. Disponível

http://www.mma.gov.br/port/conama/legiabre.cfm?codlegi=321

BRASIL. Decreto no 5.940, de 25 de outubro de 2006. Institui a separação dos resíduos recicláveis descartados pelos órgãos e entidades da administração pública federal direta e indireta, na fonte geradora, e a sua destinação às associações e cooperativas dos catadores de materiais recicláveis, e dá outras providências. Disponível em: http://www.planalto.gov.br/ccivil 03/ Ato2004-2006/2006/Decreto/D5940.htm 
BRASIL. Lei no 12.305, de 02 de agosto de 2010. Institui a Política Nacional de Resíduos Sólidos; altera a Lei $n^{\circ}$ 9.605, de 12 de fevereiro de 1998; e dá outras providências. Disponível em: http://www.planalto.gov.br/ccivil 03/ ato2007-2010/2010/lei/l12305.htm

BRUM, D.P.; SILVEIRA, D.D. Educação Ambiental na escola: da coleta seletiva do lixo ao aproveitamento do resíduo orgânico. Revista Eletrônica em Gestão, Educação e Tecnologia Ambiental (REGET-CT/UFSM), v. 4, n. 4: p. 608-617, 2011.

CONSELHO NACIONAL DO MEIO AMBIENTE. Resolução CONAMA 275, de 25 de abril de 2001. Estabelece o código de cores para os diferentes tipos de resíduos a ser adotado na identificação de coletores e transportadores, bem como nas campanhas informativas para a coleta seletiva. Disponível em: http://www.mma.gov.br/port/conama/res/res01/res27501.html

COSTA, T.A.C.R.; FERREIRA, D.M.M.F.; PAVÃO, V.M.; LEITE, L.O.; SIQUEIRA, L.F.; QUERINO, C.A.S.; QUERINO, J.K.A.S. Avaliação do discernimento dos alunos de escolas públicas a respeito de coleta seletiva. Revista EDUCAmazônia, ano 7, v. 12, n. 1: p. 28-41, 2014.

De CONTO, S.M. Gestão de resíduos em universidades. Caxias do Sul (RS), Editora EDUCS, 2010.

MAGALHAES, M.A.; MAGALHÃES, A.BS.; MATOS, A. T. Levantamento e diagnóstico das condições sócio-econômicas e culturais dos catadores de lixo e do mercado de recicláveis no município de Viçosa - MG. In: Anais do II Congresso Mundial de Educação Ambiental. Rio de Janeiro - RJ, 2004.

MANDELLI, S.M.C. Variáveis que interferem no comportamento da população urbano no manejo de resíduos sólidos domésticos no âmbito das residências. Tese (Doutorado em Educação) - Universidade Federal de São Carlos. São Carlos, UFSCar, 1997. $267 \mathrm{f}$.

SEGURA, D. S B. Educação Ambiental na Escola Pública: da curiosidade ingênua a consciência crítica. São Paulo, Annablume: Fapesp, 2001.

SILVA, M.S.F.; JOIA, P.R. Educação Ambiental: a participação da comunidade na coleta seletiva de resíduos sólidos. Revista Eletrônica da Associação dos Geógrafos Brasileiros. Três Lagoas - MS, n. 7, ano 5: p. 122-152, 2008. 